\title{
Diversity in Genetic Counseling: Past, Present and Future
}

\author{
Ilana Suez Mittman • Katy Downs
}

Received: 29 March 2007 / Accepted: 20 March 2008/Published online: 17 June 2008

(C) National Society of Genetic Counselors, Inc. 2008

\begin{abstract}
Despite decades of efforts to increase ethnic and racial diversity among genetic counselors, African Americans, Hispanics and American Indians, currently constituting almost one-third of Americans, remain only meagerly represented among genetic counselors at a level far under that seen in other health professions. This paper provides the first comprehensive effort to archive published and unpublished initiatives to increase ethnic and racial diversity in the profession. It also provides a review of national data and diversity initiatives in the health workforce in general. The paper reviews diversity initiatives in other health professions and suggests ways to improve recruitment and retention of underrepresented populations into genetic counseling. Increasing the diversity of the genetic counseling workforce stands not only to expand access to genetic services but also to improve the quality of genetic care provided to the American public.
\end{abstract}

I. S. Mittman

Department of Epidemiology and Preventive Medicine, University of Maryland,

Baltimore, MD, USA

\section{K. Downs}

Department of Otolaryngology-Head \& Neck Surgery, University of Michigan,

Ann Arbor, MI, USA

\section{K. Downs}

Wayne State University School of Medicine,

Detroit, MI, USA

I. S. Mittman ( $\square)$

Maryland Department of Health and Mental Hygiene, Office of Minority Health and Health Disparities,

807 S Clinton Street,

Baltimore, MD 21224, USA

e-mail: ilana.mittman@gmail.com
Keywords Genetic counseling · Diversity · Health disparities · Recruitment · Retention · Minority · Under represented minorities (URM)

\section{Introduction}

This paper examines professional issues pertaining to diversity in the genetic counseling profession. Included are a review of professional policies, activities, and strategic plans pertaining to diversity and an examination of similar issues in other health professions. While in genetic counseling (as in most health occupations) diversity is mostly regarded in terms of ethnicity, race and gender, it is important to recognize that everybody contributes to diversity because each one of us is different from the majority in at least one way. The assumption that diversity pertains only to socially visible groups of people is as false as assuming that racial and cultural issues are inherent domains of certain groups only.

In this paper, we focus on ethnic and racial diversity, especially pertaining to African Americans, Hispanics and Native Americans, because these groups' limited representation in genetic counseling is persistent, has not changed over decades of interventions, and is very significant in comparison to some professions. However, we recognize the significance of inclusion and diversity in a broadened scope, and hope that this paper will contribute to building a conceptual framework for this very important matter.

\section{The Case for Health Workforce Diversity}

Ethnic and racial minorities suffer significant and persistent health disparities regarding preventable and treatable conditions in comparison to other populations (IOM 2002). As illustrated by a landmark report released by the Institute of Medicine in March 2002, health disparities persist even when controlling for insurance status, disease severity and site of care; 
furthermore, the authors of this report postulate that "stereotyping, biases, and uncertainty on the part of healthcare providers can all contribute to unequal treatment" (IOM 2002: 1). Recommendation 5-3 of the IOM report calls to "increase the proportion of underrepresented US racial and ethnic minorities among health professionals."

A preponderance of scientific evidence supports the importance of diversifying health professions. For instance, data illustrate that greater diversity among health professionals is associated with increased access to care, greater patient choice and satisfaction, and better patient-provider interactions (IOM 2004). Moreover, there is compelling evidence that when minority patients are afforded choice they are more likely to choose race-concordant providers, even when controlling for office location (Association of American Medical Colleges 2006b; Price et al. 2005; Saha et al. 2000). Importantly, it has been shown that minority providers are more likely to practice in medically under-served areas and to treat indigent patients (Komaromy et al. 1996; Moy and Bartman 1995). Lastly, a diverse workforce enriches the educational experience of all as it challenges stereotypes, enhances cultural competence and fosters lasting relationships (Cohen et al. 2002; Friedman 2007; Lee and Coulehan 2006). In summary, increasing the number of underrepresented minorities in the health professions increases access to services for all populations and enhances the cultural competency of all providers; it thus constitutes a key strategy for reducing health disparities (Betancourt et al. 2003).

Special Considerations for Diversity in Genetic Counseling

Unique considerations related to the provision of genetic services, public perceptions related to genetic technology and the lag between technological discoveries and understanding of their ethical, social and legal implications, all make a compelling case for the diversification of the genetic workforce. The new genomics reframes personhood, parenthood, views of illness and disease and even ancestral identity (Bell 1998; Dolgin 2000). Genetic counseling thus involves extremely sensitive issues, which challenge worldviews, cultural practices and the ways in which individuals view themselves, whole communities and one another. While genomic medicine stands to enhance disease identification, treatments and cures, ethnic and racial minorities have limited access to quality care in genetics (Lin-Fu et al. 2000).

Demographics of Race and Ethnicity in Genetics and the General Health Workforce

The Association of American Medical Colleges (AAMC) coined the term "Under Represented Minorities" in higher education (URM) to consist of racial and ethnic populations that are underrepresented in the medical profession relative to their numbers in the general populations (Dennery 2006). Using this definition, this paper identifies African Americans/Blacks, Latinos/Hispanics and American Indians/ Alaskan Native as groups that have traditionally been vastly under-represented in health careers, and especially in genetic careers, when considering their make-up in the U.S. population. For example, while these populations represent almost one-third of Americans, they comprise less than $9 \%$ of nurses, $6 \%$ of physicians and $5 \%$ of dentists (Sullivan 2004). In 2006, these populations were estimated to comprise $3 \%$ of genetic counselors.

An Overview of Ethnic and Racial Demographics in Genetic Professions

The NSGC Professional Status Surveys (PSS) conducted between 1992 and 2006, demonstrate a predominance of non-Hispanic white genetic counselors ranging from 9194.2\% of the total membership (Boldt 1994; Parrott and Del Vecchio 2007; Doyle 1996; Farmer 2000; Parrot and Manely 2004; Parrott and Del Vecchio 2007; Schnieder 1998; Uhlmann 1992). As illustrated in Fig. 1, professional membership by African Americans and Hispanics has stayed steady at $1 \%$ each for well over a decade and together reached $2.9 \%$ in 2006. In contrast, greater accomplishments in increased diversity have been achieved for Asian Americans in the profession as this population experienced more than a three-fold increase since 1992. Information regarding future diversity in the genetic counseling profession can be gleaned from a study examining demographics and career related information for students enrolled in 27 genetic counseling training programs in North America (Lega et al. 2005). African Americans and Hispanics constituted 3\% of the students surveyed. Similar to the NSGC, other professional genetics societies have a meager representation of URMs. Data obtained for 2007 from the American Society of Human

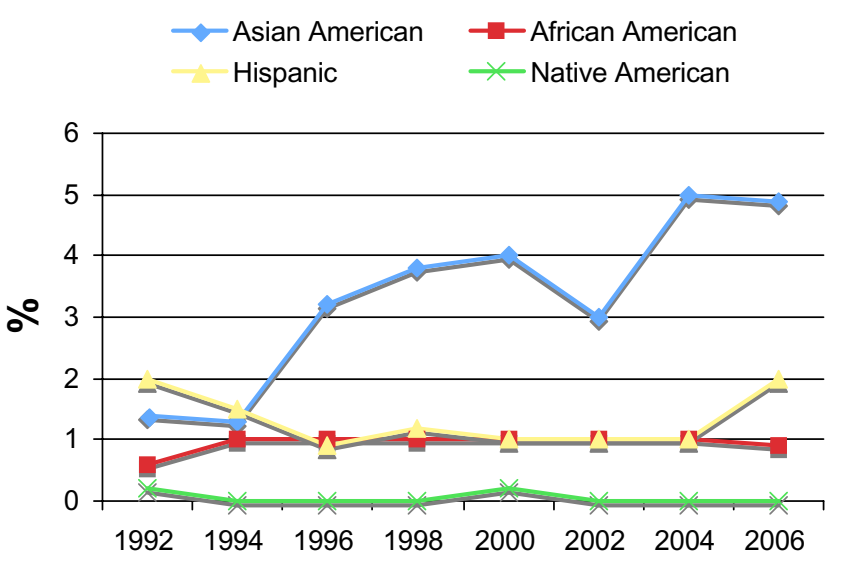

Fig. 1 NSGC Membership Trends by "Ethnic/Racial" Status, 19922006. Source: NSGC Professional Status Surveys 1992-2006 (PSS). 
Genetics (ASHG) revealed that African Americans and Hispanics comprised $1.47 \%$ and $3.15 \%$ of the membership, respectively (personal communications, 3/5/07).

Specific ethnic and racial demographics for members of the American Board of Medical Genetics (both $\mathrm{PhD}$ and MD level) are available from a 3-year national research project designed to assess genetic services (Cooksey et al. 2005; Cooksey et al. 2006). The study established that the vast majority of both $\mathrm{MD}$ and $\mathrm{PhD}$ clinical geneticists were white; African Americans comprised only 1\% of both MD and $\mathrm{PhD}$ geneticists, and Hispanics made up only $2 \%$ of both groups.

The International Society of Genetic Nurses (ISONG) does not currently collect ethnic and racial data from its members. However, a 2004 cross-sectional descriptive survey of US genetic nurses revealed that only $6 \%$ were ethnic and racial minorities (Lea et al. 2006).

\section{Membership in Other Allied Health Professions}

In comparison to other mental health and health care professionals, genetic counselors are among the least likely to be African American, Native American or Hispanic. As shown in Table 1, information from the Bureau of Labor Force Statistics suggests that the genetic counseling profession is among health professions with the lowest participation of African Americans and Hispanic Americans compared to a host of medical and allied health professions (Kosanovich 2006).

Barriers to Participation of Ethnic and Racial Minorities in Health Professions

Entering and graduating from a health professional school happens at the "downstream" end of an educational pipeline that starts with an individual's earliest school experience. For minorities, this pipeline is "leaky" at multiple points.
Overt public policies prohibiting or limiting access to educational opportunities based on race are part of our national history. Slavery, segregation, substandard educational opportunities in economically depressed areas and the recent challenges to race conscious admissions have placed minorities at a distinct educational disadvantage (Barnes 2007; Cordes and Miller 2005; Educational Broadcasting Corporation 2004). On average, when compared with White students, racial and ethnic minorities receive a K-12 education of measurably lower quality, score lower on standardized tests, and are less likely to complete high school. Moreover, those who graduate from college are far less likely to graduate from a 4-year college than their White counterparts (Cohen 2005).

A multitude of barriers to academic success among minorities is cited in the literature. These include social vulnerability as minority students often recount feelings of isolation, and lack of support in predominantly white institutions (Gardner 2005a, b; Gilchrist and Rector 2007; Maton and Hrabowski 2004). There are also issues of lack of academic preparation leading to poor study habits and inadequate test taking skills (Gilchrist and Rector 2007). Lack of adequate minority faculty presents another key barrier to a successful academic experience for minorities as it limits the availability of guidance and mentorship for individuals who may be the first in their families to attain higher education (Moreno et al. 2006). Financial barriers significantly limit access to higher education among minorities. The cost of application, tuition and ancillary fees as well as the financial impact of deferring a steady income may be detrimental in accessing higher education especially for individuals who lack family support, and/or are supporting others. Finally, lack of exposure of ethnic and racially diverse youth to the scope of health careers is a major deterrent to their entering such professions (Gonzalez et al. 2000; Marcelin et al. 2004; Stewart et al. 2002; Thomson et al. 1991).

Table 1 National Data on Health Workforce Diversity, by Gender, Race and Ethnicity

\begin{tabular}{|c|c|c|c|c|c|}
\hline Profession & Men $(\%)$ & African American $(\%)$ & Hispanic/Latino (\%) & Asian American (\%) & Total minorities $(\%)$ \\
\hline Social workers & 22.3 & 20.4 & 10.9 & 2.9 & 34.2 \\
\hline Clinical laboratory technicians & 28 & 14.6 & 6.9 & 10.2 & 31.7 \\
\hline Physician assistants & 32.7 & 6.8 & 9.4 & 7.6 & 23.8 \\
\hline Registered nurses & 7.8 & 10.1 & 4.4 & 6.8 & 21.3 \\
\hline Physical therapists & 34.6 & 7.1 & 3.3 & 10.3 & 20.7 \\
\hline Occupational therapists & 7.3 & 5.1 & 3.7 & 8.8 & 17.6 \\
\hline Medical geneticists & 50.0 & 1.0 & 2.0 & 8.0 & 11.0 \\
\hline Psychologists & 33.3 & 3.3 & 4.6 & 1.4 & 9.3 \\
\hline Speech language pathologist & 4.9 & 6.0 & 2.1 & 0.5 & 8.6 \\
\hline Genetic counselors & 9.0 & 1.0 & 1.0 & 5.0 & 7.0 \\
\hline
\end{tabular}

Source: Bureau of Labor Force Statistics (2006), NSGC Professional Status Survey, 2004 
Studies Exploring Diversity in Genetic Counseling

A recent qualitative study of minority genetic counselors and genetic counseling students suggested a number of contributing factors to the lack of diversity in the field (Schoonveld et al. 2007). These include a lack of professional appeal because of lower than desired salary levels and a view that the profession does not hold true value for underserved communities. Additional reasons included lack of awareness of the genetic counseling profession as most minority counselors stated that they "stumbled upon" the profession almost accidentally. Lastly, respondents articulated a notion of isolation and being "alone" in a profession which is not only composed of predominantly Caucasian counselors but also tends to serve ethnic/racial majority populations.

$\mathrm{Oh}$ and Lewis (Oh and Lewis 2005) surveyed high school and college students regarding their awareness of genetic counseling as a career choice and their interest in enrolling in such a career. These researchers found that early awareness of genetic counseling is helpful in making the transition from potential applicant to actual applicant. Furthermore, ethnic and racial minority students had a lower awareness of genetic counseling, but once they became aware of the profession, they reported being as likely as other students to choose genetic counseling.

Other efforts to identify barriers related to diversity in the genetic counseling profession include an earlier survey of program directors, and a recent survey of high school and college students. In 1993, Smith and colleagues conducted a needs assessment, surveying genetic counseling training programs about the feasibility of enhancing minority recruitment into genetic counseling graduate programs (Smith et al. 1993). Retrospective data revealed that between 1982 and 1992 a total of 730 persons were admitted into genetic counseling training programs in the USA. Of these, the total number of minority students was 62 (8.4\%). Furthermore, respondents indicated that almost no efforts were devoted to recruitment from minority colleges and that all of the minority enrollees in genetic counseling programs sought out those programs themselves. The two most frequently cited barriers to entering the genetic counseling profession by study participants were lack of information about the profession and tuition cost.

Lega et al. (2005), in their survey of genetic counseling student demographic characteristics, found that among the students who responded to their survey, $56.2 \%$ came from households with annual income exceeding \$80,000/year. Moreover, $71 \%$ of the fathers and $65.6 \%$ of the mothers of study participants had at least a college degree or higher education. As mentioned earlier in this paper, financial barriers are frequently cited as barriers to entering higher education among ethnic minorities. It is likely that some potential applicants would be living in homes with lower annual household incomes. Furthermore, they may be first in their household to have obtained undergraduate and graduate degrees.

\section{Efforts to Increase Diversity in Genetic Counseling: An Historical Overview ${ }^{1}$}

The NSGC has documented its commitment to diversity in both its Access to Care Position Statement and Code of Ethics, both critical core publications of the profession. The Position Statement supports access to care "regardless of racial or ethnic background" (NSGC 1991). The Code of Ethics states in section II-3 that genetic counselors strive to 'Respect the clients' beliefs, inclinations, circumstances, feelings, family relationships and cultural traditions" (NSGC 1992). In addition, racial and cultural issues are specifically addressed in the communication skills section of the American Board of Genetic Counseling as one of the required practice-based competencies:"...caring for clients using cultural self-awareness and familiarity with a variety of ethnocultural issues, traditions, health beliefs, attitudes, life styles, and values" (Fine et al. 1996).

Numerous diversity initiatives took place in the past two decades involving the entire society, its leadership, the membership committee, training program directors, special interest groups, and individual members. Some of these efforts are illustrated in detail in the following segment and others are listed in Table 2. The account of events in this paper is a first attempt to document efforts related to diversity within the genetic counseling profession. It is based on review of the literature, and documentation available through the NSGC executive office, members of the NSGC Diversity Special Interest Group (SIG) and informal interviews of professional members who have witnessed or participated in events. We caution the readers that this account may not be complete and invite comments and added information.

Shortly after its incorporation, the NSGC conducted its first Professional Issues Survey. In 1998 the NSGC's newsletter, Perspectives in Genetic Counseling, reported that $90 \%$ of 150 respondents to an annual survey were females. The reported demographics included sex and geographic area of practice, but did not mention race, ethnicity or other characteristics specific to underrepresented populations. The first mention of ethnic/racial diversity among genetic counselors was during a presentation given by a group of minority counselors at the NSGC's annual conference in 1985. These individuals estimated that there

\footnotetext{
${ }^{1}$ Initiatives directed toward increasing diversity in the field are outlined in Table 2.
} 
Table 2 Highlights of Past Efforts to Increase Diversity in the Genetic Counseling Profession

\begin{tabular}{|c|c|c|}
\hline Year & Effort & Initiated and/or supported by \\
\hline \multirow[t]{2}{*}{1979} & $\begin{array}{l}\text { NSGC By laws designate six regions to ensure geographic representation } \\
\text { on Board of Directors }\end{array}$ & By Laws Committee \\
\hline & $\begin{array}{l}\text { Criteria for full membership expanded to include professionals in addition } \\
\text { to those with masters in genetic counseling }\end{array}$ & By Laws Committee \\
\hline $1980 / 1981$ & $\begin{array}{l}\text { First Professional Issues Survey collects demographic data on membership } \\
\text { including sex and geographic area }\end{array}$ & Professional Issues Committee NSGC \\
\hline 1991 & $\begin{array}{l}\text { "Encouragement of diversity in the field of genetic counseling" sighted } \\
\text { as vision for the profession }\end{array}$ & $\begin{array}{l}\text { Ad hoc Long Range Planning } \\
\text { Committee, International Congress } \\
\text { of Human Genetics }\end{array}$ \\
\hline 1992 & $\begin{array}{l}\text { Ethnocultural Issues in Genetic Counseling Recruitment and Education } \\
\text { conference for Program Directors }\end{array}$ & Education Committee NSGC \\
\hline \multirow[t]{4}{*}{1993} & $\begin{array}{l}\text { Diversity Among Genetic Counselors Subcommittee formed to encourage } \\
\text { "more heterogeneity within our profession, targeting groups currently underrepresented: } \\
\text { racial, ethic and culture minorities, men and those with disabilities. In existence } \sim 2 \text { years }\end{array}$ & Genetic Services Committee, NSGC \\
\hline & $\begin{array}{l}\text { "Ethnocultural diversity and genetic counseling training: The challenge for } \\
\text { a twenty-first century" published }\end{array}$ & $\begin{array}{l}\text { D Punales-Morejon and R Rapp, } \\
\text { Journal of Genetic Counseling (JGC) }\end{array}$ \\
\hline & "Minority recruitment into the genetic counseling profession" published & $\begin{array}{l}\text { SC Smith, NS Warren and L Misra } \\
\text { JGC }\end{array}$ \\
\hline & $\begin{array}{l}\text { Mailing targeted to undergraduates attending Historically Black Colleges and } \\
\text { Universities (HBCU's) with cover letter encouraging applications from qualified } \\
\text { individuals of all ethnocultural groups }\end{array}$ & $\begin{array}{l}\text { Jon Weil Membership Committee } \\
\text { NSGC }\end{array}$ \\
\hline 1994-1997 & $\begin{array}{l}\text { Genetic Services Branch of the Maternal and Child Health Bureau awarded } \\
3 \text { year grant "Genetic-LINC; Liaisons Into Cultures" }\end{array}$ & $\begin{array}{l}\text { Ilana Mittman Baltimore Sinai } \\
\text { Hospital and Howard University }\end{array}$ \\
\hline \multirow[t]{3}{*}{1996} & $\begin{array}{l}\text { Meeting agenda included: Recruitment: increase and retain the membership } \\
\text { of the NSGC, with special attention to minorities and students }\end{array}$ & Membership Committee NSGC \\
\hline & $\begin{array}{l}\text { Dissemination of NSGC college recruitment poster targeted to quality minority } \\
\text { undergraduate institutions and to specific areas of the country }\end{array}$ & Membership Committee NSGC \\
\hline & $\begin{array}{l}\text { Set objective to identify minority-focused college career guidebooks and internet } \\
\text { sites in which to list genetic counseling as a career }\end{array}$ & Membership Committee NSGC \\
\hline 1997 & Slide presentation to encourage minority applications & $\begin{array}{l}\text { Stacey Wong and Arlyn Tanega, } \\
\text { graduate students at Northridge }\end{array}$ \\
\hline 1997 & Diversity SIG formed & NSGC members \\
\hline 1998 & Strategic Plan included "encourage diversity" & NSGC \\
\hline 1999 & Diversity Task Force (DTF) appointed & Wendy Uhlmann, President NSGC \\
\hline 2000 & $\begin{array}{l}\text { DTF survey sent to all NSGC members } \\
\text { DTF final report submitted to NSGC Board of Directors (BOD) }\end{array}$ & \\
\hline 2003 & Diversity SIG reformed into Diversity Subcommittee of Membership Committee & $\begin{array}{l}\text { Kathryn Spitzer Kim Membership } \\
\text { Committee NSGC }\end{array}$ \\
\hline 2004 & $\begin{array}{l}2004-2006 \text { Strategic Plan included a goal to "Increase visibility of genetic counseling } \\
\text { as a profession with emphasis on diversity" with the tactic to "Identify and implement } \\
\text { effective recruitment methods" and the related outcomes to " } 1 \text {. Achieve plan for minority } \\
\text { recruitment } 3 / 05 \text {; Implement plan by } 6 / 05 ; 2 \text {. Achieve increase in minority representation } \\
\text { by } 9 / 06 \text { " }\end{array}$ & NSGC \\
\hline 2005 & Genetic counselor and students featured on "sistagirls.org" website & Katy Downs Diversity Sub-Committee \\
\hline 2005-2006 & Career brochures developed for minority recruitment & $\begin{array}{l}\text { N Steinberg Warren Membership } \\
\text { Committee }\end{array}$ \\
\hline 2006 & $\begin{array}{l}\text { Community outreach to primarily African American undergraduate students held } \\
\text { during the } 2006 \text { AEC in a community location }\end{array}$ & $\begin{array}{l}\text { Tené Hamilton Franklin Diversity } \\
\text { Subcommittee NSGC }\end{array}$ \\
\hline
\end{tabular}

were no more than 30 practicing minority genetic counselors at that time (verbal communications). Since the total NSGC membership was 593 in 1985, minority representation in the profession was $5 \%$.

In 1991, a sub-committee of the NSGC education committee received funding from the Office of Human
Genome Research in the National Institute of Health, for Ethical, Legal and Social Implications (ELSI) project. This funding supported a 3-day conference in 1992, in Asilomar, California, to bring together program directors of all genetic counseling training programs to explore ethnocultural issues in genetic counseling and recruitment and retention 
of under-represented groups in the profession. Following these deliberations, the Journal of Genetic Counseling devoted an entire issue in September of 1993 to the challenges of ethnocultural diversity and training including a report on minority recruitment and suggestions for developing a cross-cultural curriculum. Additionally, in 1993, the membership committee coordinated a mass mailing of career packets and a cover letter promoting genetic counseling careers to 1,000 college academic guidance offices, and biology and psychology departments nationally.

A 2-day meeting of the NSGC Board of Directors in 2003, led to the development of the NSGC's Strategic Plan of 2004-2006. The plan focused on three strategic initiatives: (1) genetic counseling service delivery; (2) NSGC visibility; and (3) billing and reimbursement. Within the NSGC visibility initiative, sub-section 2-1E states "increase visibility of genetic counseling as a profession with emphasis on diversity." The objectives included achieving a plan for minority recruitment by March of 2005 , and implementing that plan by June of 2005 with an expected increase in minority representation by September of 2006 (NSGC 2003).

\section{The Diversity Special Interest Group (SIG)}

A new chapter in NSGC's formal recognition of the importance of diversity began with the formation of the Diversity Special Interest Group (SIG). This group has been in existence continually from 1997 to 2003 when it reformed as the Diversity Subcommittee of the Membership Committee. From its onset, one tenet of the Diversity SIG was inclusiveness as demonstrated in its original charge to provide culturally diverse genetic counselors and counseling students the support they need to succeed in the profession (Mittman 1997). It is important to note that the Diversity SIG embraced an expanded concept of the term "diversity" to include counselors with a diverse background related to places of origin, language spoken, sexual orientation, ethnic and racial background, gender, age, and disability status.

The Diversity SIG and later the Diversity Sub-Committee championed numerous activities embracing diversity including fostering collaborations with community groups during the NSGC's annual meetings, spearheading the Speakers Bureau project, Student Awards programs, development of recruitment brochures and many others innovative projects to increase diversity and inclusion. During the time that this paper was being developed, there was discussion about restructuring diversity-related efforts to allow them to be incorporated into all NSGC functions. To that end, the Diversity Subcommittee will most likely be phased out (personal communication).
The 1997 Survey of Genetic Counseling Training Programs Directors (Unpublished Data)

In October of 1997, the Association of Genetic Counseling Program Directors of the NSGC conducted a minority recruitment workshop for program directors to discuss the issues of minority recruitment into the genetic counseling profession. The workshop was sponsored by the National Human Genome Research Institute (NHGRI). Forty-five representatives of 21 genetic counseling training programs from the USA and Canada attended, representing all American Board of Genetic Counseling accredited training programs in the USA and one Canadian program.

The keynote speaker for the event was Freeman A. Hrabowski, PhD, President of the University of Maryland at Baltimore County (UMBC), and engineer of the Meyerhoff Scholarship Program, which is nationally recognized for its success in encouraging the participation of African Americans in science and engineering. Prior to the event, program directors received a set of questions regarding minority recruitment. Questions included: (1) What populations were identified as ethnic minorities and therefore entitled to financial assistance if any? (2) Is there a minority recruiter in the institution? and (3) What steps does the program take to enhance minority recruitment?

Each program completed only one survey, and responses were received from 21 training programs $(91.3 \%$ response rate). The results of the survey revealed that while three quarters of Program Directors felt that minority recruitment is very important, only $19 \%$ demonstrated awareness of diversity resources within their own campus. Nine respondents $(42 \%)$ indicated that they did not take any steps toward increasing diversity. A summary of reported activities is provided in Table 3.

\section{The Diversity Task Force of 2000 (Unpublished Data)}

In January of 2000, then NSGC President, Wendy R. Uhlmann, appointed a nine member Diversity Task Force to developing strategies for encouraging individuals of differing physical abilities, gender, and diverse racial, ethnic and cultural backgrounds to enter the genetic counseling field (Uhlmann 2000). During its 1 year tenure the task force was charged with conducting a fact-finding mission and generating a report to be presented to the NSGC's Board of Directors at the 2001 Annual Educational Conference. The Diversity Task Force developed a survey which was the first, and to date, only attempt by the NSGC to collect expanded demographic data, as well as information on the "climate" of the profession with respect to diversity, and perceptions related to diversity and career advancement from its entire membership. This pioneering effort reached beyond conventional domains of age, sex, race and 
Table 3 Diversity Efforts in Genetic Counseling Training Programs in North America-Workshop on Diversity Recruitment, October 1997

\begin{tabular}{lcc}
\hline Activity & Number & Percentage \\
\hline $\begin{array}{l}\text { Presentations to minority undergraduate } \\
\text { institutions on genetic counseling }\end{array}$ & 11 & 52.3 \\
$\begin{array}{l}\text { Presentations to high schools with minority } \\
\text { students }\end{array}$ & 7 & 33 \\
$\begin{array}{l}\text { Mail information to schools with a high } \\
\quad \text { enrollment of minority students }\end{array}$ & 5 & 23.8 \\
$\begin{array}{l}\text { Outreach education to biology teachers in } \\
\text { high schools }\end{array}$ & 3 & 14.2 \\
$\begin{array}{l}\text { Present at career fairs } \\
\text { Have minority graduate students take part in } \\
\text { recruitment }\end{array}$ & 3 & 14.2 \\
$\begin{array}{l}\text { Establish a special fund for minority } \\
\text { students }\end{array}$ & 1 & 9.5 \\
$\begin{array}{l}\text { Establish a minority graduate advisory } \\
\text { committee on recruitment }\end{array}$ & 1 & 4.7 \\
No activities reported & 9 & 42.8 \\
\hline
\end{tabular}

$N=21$ programs

ethnicity by expanding areas of diversity to include: country of origin, language(s) spoken, religious affiliation, disability, sexual orientation, presence of a genetic condition, and socioeconomic status as they pertain to perceived discrimination, recruitment strategies, and professional status. In addition, the survey elicited perceptions of respondents' academic and professional careers as well as perceptions of discrimination pertaining to training, job seeking and career advancement. The survey was mailed to 1,705 genetic counselors, and returned by 904 (53\% response rate), with 898 surveys containing usable data.

Among other findings, demographic data revealed that $14 \%$ of respondents were foreign-born and $18.9 \%$ were bilingual. Under-represented counselors were more likely to report less satisfaction with their career trajectory, and to perceive discrimination in employment, career advancement and the training experience. Due to the age of the data (now 9 years) we wish to caution readers about the findings' relevance. However, we recommend that additional studies of genetic counselors' perceptions related to diversity be conducted. We are willing to share our survey and additional findings with interested parties.

\section{Learning From the Experiences of Others: Diversity Status in Other Health Professions}

Achieving inclusiveness regarding diversity is espoused by most academic and professional institutions but is indeed a challenging prospect. Minority participation in health professions does not follow a uniform trend. While increases in membership diversification that approach URM representation in the population at large have been shown in professions such as baccalaureate nursing, public health and pharmacy (Grumbach et al. 2003), other professions show little or no improvement. In 2004, only $6.4 \%$ of practicing US physicians were URMs (Association of American Medical Colleges 2006a). Similarly, in that year $9 \%$ of the nation's nurses (at all levels of training) and $5 \%$ of dentists were either Hispanics, African Americans or Native Americans (Sullivan 2004). Importantly, as has been shown in a government report on mental and behavioral health professions (Duffy et al. 2004) the vast majority of traditional mental health professionals such as social workers, counselors, marriage and family therapists and pastoral counselors were non-Hispanic white.

Best and Promising Practices in Increasing Minority Participation in Health Careers

Given limited resources for increasing workforce diversity, it is paramount to build upon the work of others. The Institute of Medicine (IOM) report on health disparities led to a growing awareness of career paths barriers to biomedical professions experienced by racial/ethnic minorities (Agrawal et al. 2005; Association of American Medical Colleges 2006a; Brady 2004; Institute of Medicine 2001, 2004). A review of the medical literature for minority recruitment efforts in the health workforce predominantly yielded publications pertaining to schools of medicine and nursing. Publications on minority recruitment into various counseling professions are surprisingly sparse. For that reason we will mostly draw on experiences in diversifying medical and nursing education and experiences pertaining to enrolling minorities into science major tracks at the undergraduate level. In general, successful strategies for increasing diversity in the various health professions include pipeline preparation of inner city students for Science, Engineering, Technology and Math (STEM); dispelling myths about science and medical careers; making available early faculty and peer mentoring; offering precollege summer programs, as well as post-baccalaureate preparation for graduate education; financial assistance such as scholarship and Loan Forgiveness programs, and, creating a hospitable climate for minority students in predominantly white institutions (Cohen and Steinecke 2006; Grumbach and Chen 2006; Maton and Hrabowski 2004; Table 4).

\section{Diversity in Medical Education}

The AAMC has been diligent and tenacious in its efforts to diversify medical education. Project " 3,000 by 2,000" presents the most comprehensive effort to increase diversity 
Table 4 Suggested National Resources on Diversity in Health Careers

\begin{tabular}{|c|c|}
\hline Name & Contact Information \\
\hline American Indian Higher Education Consortium & http://www.aihec.org/ \\
\hline Asian American Pacific Islander Health Forum & http://www.apiahf.org/ \\
\hline Association of Minority Health Professions Schools & http://minorityhealth.org/about.html \\
\hline Health Careers Opportunity Programs & http://bhpr.hrsa.gov/diversity/hcop/default.htm \\
\hline Health Professionals for Diversity Coalition & http://www.hpd-coalition.org/ \\
\hline Health Professions Partnership Initiatives & http://www.hppi-2020.org/ \\
\hline Hispanic Association of Colleges and Universities & http://www.hacu.net/hacu/Default_EN.asp \\
\hline Hispanic Serving Health Professions Schools & http://www.hshps.com/ \\
\hline Historically Black Colleges and Universities & http://www.smart.net/ pope/hbcu/hbculist.htm \\
\hline HRSA-Kids Into Health Careers & http://bhpr.hrsa.gov/kidscareers/ \\
\hline HRSA-The Bureau of Health Professions/Diversity Initiative & http://bhpr.hrsa.gov/diversity/mffp/defualt.htm \\
\hline Minority Access, Inc. & www.minorityaccess.org \\
\hline National Alaska Native American Indian Nurses Association & http://www.nanainanurses.org/ \\
\hline National Association of Advisors for the Health Professions & http://www.naahp.org/ \\
\hline National Association of Hispanic Nurses & http://thehispanicnurses.org/ \\
\hline National Association of Medical Minority Educators (NAMME) & http://www.paeaonline.org/namme.htm \\
\hline National Coalition of Ethnic Minority Nurse Associations & http://www.ncemna.org/ncemna/scholarships.asp \\
\hline Philippine Nurses Association of America & http://www.pnaa03.org/04_7_Awards_Scholarship.html \\
\hline The Biology Scholars Program & http://bsp.berkeley.edu/ \\
\hline The Diversity Pipeline Alliance & http://www.diversitypipeline.org/ \\
\hline The Meyerhoff Scholarship Program & http://www.umbc.edu/meyerhoff/ \\
\hline The National Association of Equal Opportunity in Higher Education & http://www.nafeo.org \\
\hline The National Black Nurses Association & http://www.nbna.org/ \\
\hline The Sullivan Alliance to Transform America's Health professionals & http://www.jointcenter.healthpolicy/commission.php \\
\hline
\end{tabular}

representation in medical education (Terrell and Beaudreau 2003). The project, launched by the AAMC in 1991 to address the declining representation of minorities in medical education had a two-pronged approach; that of identifying talented youth interested in a medical career and providing them with academic enrichment opportunities, and the establishment of a broad based infrastructure to help nurture and sustain minority medical students once enrolled. In the first 4 years of the project's operation the number of minority matriculates into medical schools increased by almost $40 \%$. However, legal challenges to affirmative action and subsequent bans on the use of racebased admissions are blamed in the project's failure to achieve its targeted goal by 2000 (Terrel and Beaudreau 2003). One of the key elements for success of project 3,000 by 2,000 was its broad educational campaign to engage deans and administrators of schools of medicine, thus resulting in high levels of participation by these schools. Another key element for the project's success was the significant funding for its activities orchestrated by the AAMC from private funding agencies.

Post-baccalaureate programs nurturing college graduates into successful applications to health professional schools have been particularly promising showing remarkable success. In a California model program, students who participated in post baccalaureate programs were over six times more likely to matriculate into medical school when controlling for grade point average and demographic characteristics (Grumbach and Chen 2006).

In the fall of 2006, the AAMC released its analysis illustrating that while more minority students are graduating with biology degrees (which are the most popular majors for medical school applicants), fewer of these students are now applying to medical schools (Association of American Medical Colleges 2006b). To encourage application to medical school the AAMC launched a massive campaign entitled "AspiringDocs.Com" which seeks to encourage eligible minorities from all undergraduate majors to pursue a career in medicine (Association of American Medical Colleges 2006c). The campaign provides a rich web-based environment that assists potential medical school applicants in a host of areas ranging from MCAT exam preparation to application logistics and financial support.

\section{Diversity in Nursing Education}

Despite national trends of increasing diversity, ethnic and racial minorities are currently underrepresented in the nursing profession (Barbee and Gibson 2001; Bumgarner et al. 2003; Fletcher et al. 2003; Gardner 2005a, b; Gilchrist and Rector 2007; McNeal and Walker 2006). One factor contributing to the under-representation of minorities in the 
nursing profession is the high rate of attrition of minority students from training programs in nursing estimated to range from $15 \%$ to $85 \%$ (Gardner 2005a, b).

Facing critical issues of workforce shortage, lack of desired diversity, problems in retention of minority nursing students, and shortage of mentors in general and minority mentors in particular, nursing programs around the country have taken various action strategies. Several nursing schools have established mentoring programs that match first and second year students with advanced nursing students. Schools have also revised their nursing curricula to include cultural competency training, increased focus on holistic approaches to patient care, and service learning opportunities for their students through partnering with diverse communities. Nursing schools are also increasing the accessibility of their classes to individuals who have both work and home obligations by providing distant learning opportunities, after hour classes, and off campus classroom locations. Some schools have set aside special funds for minority students and many nursing scholarships organizations also offer financial awards (All Nursing Schools 2007).

\section{Science, Technology, Engineering and Math (STEM)}

There are several programs in the nation that boost college level interest and preparation in biomedical careers such as the Meyerhoff Scholars Program at the University of Maryland Baltimore County, and the Biology Scholars Program at the University of California Berkeley (Maton and Hrabowski 2004; Matsui et al. 2003). These programs employ strategies that include on-going rich mentorship, study group participation, and extended opportunities for research. Their success is demonstrated by recent data showing that ethnic and racial minorities are not only as interested as their peers in pursuing college-level science studies, but they also increasingly are choosing biology and sciences majors in college, and demonstrating a greater likelihood of enrolling in graduate studies in these subjects (Raymond and Lue 2006).

\section{Discussion}

Despite over two decades of efforts to increase diversity among genetic counselors, the profession's gender and ethnic and racial demographics remain relatively unchanged. Findings from the study of Lega et al. (2005) indicate that we can expect little change in the next few years. Moreover, data reported by the American Society of Human Genetics, International Society of Genetic Nurses, and the American Board of Medical Genetics, all confirm similar levels of extremely low participation of underrepresented minorities in genetic careers.
As illustrated earlier, the problem is not unique to the genetic counseling profession since higher-paying, betterknown professions similarly are struggling to recruit and retain minorities. However, a level of $2-3 \%$ representation of African Americans, Hispanic Americans and Native Americans among genetic professionals, when these groups' constitution in the US population is ten times as high, is rather disquieting.

While this paper describes an impressive number of diversity initiatives within the profession, it is our opinion that they are disjointed, sporadic, and variously lack realistic goals and effective implementation and evaluation strategies. For example, the Strategic Plan of 2004-2006 created a timeline that was doomed to failure. It called for implementation of a minority recruitment plan 3 months after it was developed and then a demonstration of increased diversity in just 1 year from implementation. Considering the labor intensive process of increasing awareness among potential applicants, the application and enrollment process, and then 2 years of graduate training, such a timeline is not realistic. Indeed it needs to be recognized that there are no "quick" fixes for a situation that has been long in the making; rather, perseverance and patience will prove rewarding.

The few attempts made to explore reasons for the low percentage of ethnic and racial minorities in the field tend to focus on recruitment and training. When exploring the under-representation of ethnic/racial minorities in the genetic counseling profession it is imperative to look not only at recruitment per se, but also at retention, training experience, professional "climate" in general, and specifics related to mentoring, job satisfaction and career advancement. Such issues are key to retention and career satisfaction.

Oh and Lewis (2005) proposed the Genetic Counseling Career Pathway Model (GCCPM), which focuses on promoting awareness of the genetic counseling profession leading to application to graduate programs and progression from training into graduation and employment. However, their model fails to include career track progression and job satisfaction which are important factors in assuring not only retention of minority genetic counselors but also the availability of minority role models and mentors.

Schoonveld et al. (2007) illustrated that racial minority counselors are presumed to be "spokes persons" on diversity issues and are expected to demonstrate advocacy in these areas. Their findings raise an important issue regarding career opportunities for under-represented minorities. Will these individuals be able to freely pursue their areas of interest, or will they feel obligated to participate in activities not of their choosing, thereby detracting from other areas of career building?

Training costs and perceived earning potential seem to be obstacles to recruitment of racial minorities into genetic 
counseling (Schoonveld et al. 2007; Smith et al. 1993). Moreover, Lega et al. (2005) demonstrated that genetic counseling students are disproportionately from affluent backgrounds as well as households where at least one parent holds some type of an advanced degree. It is possible that persons who are the first generation in their family to attain higher education aspire for "highly visible," prestigious health professions, as well as those with a higher level of reimbursement such as medicine. Additionally, persons who are the first in their families to pursue higher education may lack knowledge about the "preferred" etiquette of application procedures, networking and career building as well as adaptive behaviors while in training programs. These issues could place applicants in a disadvantage and they should be explored in future studies. Mentorship and post baccalaureate training programs may assist aspiring under-graduate students to prepare for a career in genetic counseling.

\section{Recommendations}

The following recommendations address three areas: (1) institutional recommendations; (2) research recommendations; and (3) educational recommendations.

\section{Institutional Level}

Changing the ethnic and racial composition of the genetic counseling profession will necessitate making diversity as a whole a priority backed up by a proactive and ongoing commitment at the organizational level. Again, we must recognize that diversity applies to each and every aspect of the profession. A "siloed" approach to a complicated issue that is most effectively addressed through multi-faceted strategies and interventions is counter-productive. To be effective, the leadership will need to actively incorporate strategies that foster an inclusive environment in all domains of the profession including professional policy for internal and external affairs, outreach education, recruitment, training, mentoring, service delivery, and career advancement.

\section{Integration and Coordination}

There are multiple initiatives that address diversity recruitment in the NSGC and ASHG. However, what is missing is a component that will keep these various activities integrated and well coordinated. Many institutions are now identifying "Chief Diversity Officers" who oversee the development, implementation and evaluation of all diversity measures. Having such a function at the top of the hierarchy of the profession may help with continuity, integration and the facilitation of internal and external partnerships related to diversity. The NSGC might partner with both ASHG and ISONG in instituting such a position.

\section{Data Collection and Monitoring}

The NSGC, ASHG, ISONG, ABMG and all ABGC accredited training programs should consider a uniform data collection system that will illuminate trends in application, enrollment, attrition, graduation, performance, career trajectories, etc. A year-by-year analysis will reveal problems, showcase successes and allow for appropriate planning. It is noteworthy that in its most recent Professional Status Survey (Parrot and Del Vecchio 2007) the NSGC broadened its racial and ethnic demographic criteria to include various ethnic sub-grouping.

Research Recommendations

\section{Needs Assessment}

It is imperative to conduct a periodic needs assessment campaign to identify new and persistent barriers to accessing the profession and devise solutions to address them. Needs assessment should include not only the NSGC, but the very communities from where the next generation of genetic counselors will come. A steering committee of major stakeholders such as academic faculty, parents, minority students, guidance counselors and career advisors can be very helpful in guiding professional efforts in increasing diversity.

The perceived experiences of minority students should be of interest, and studies such as those conducted by Lega et al. (2005) and Schoonveld et al. (2007) should be extended. Additionally, the experiences of students based at predominantly white institutions should be contrasted with those training at or matriculating from Historically Black Colleges and Universities (HBCUs) such as the Howard University's genetic counseling training program.

Needs assessments should also include active and nonactive genetic counselors, members of the NSGC Board of Directors, and other professionals in order to ascertain issues related to professional climate, career advancement and job satisfaction. In general, future studies will need to over-sample genetic counselors from under represented backgrounds in order to allow for meaningful quantitative analyses. Moreover, qualitative research is needed to understand why decades of interventions have not yielded the desired results. Such methodology is most promising for engaging key informants who are immersed in the issues under investigation and should include observations, in depths interviews, focus groups and narrative analysis. 
Educational Recommendations

\section{Recruitment Strategies}

An aggressive campaign to showcase genetic careers is needed as it has been shown that intense outreach education regarding the genetic counseling profession is lacking $(\mathrm{Oh}$ and Lewis 2005; Schoonveld et al. 2007; Smith et al. 1993). The creation of an interactive web environment promoting a career in genetic counseling could prove beneficial and help disseminate information about the profession through extensive links to secondary and postsecondary educational institutions. An example could be taken from the AspiringDocs.Com campaign described earlier. The NSGC could feature a "one stop shop" approach by creating a website that provides potential applicants with tips on how they could best prepare for a genetic counseling career, application information, guidance on financial assistance, and access to a live "community" that will allow them to interact with students, program directors and professionals.

While this approach could be costly, private funding institutions such as the Robert Wood Johnson Foundation (RWJF) have made available granting mechanisms for online efforts to diversify the health workforce through its ExploreHealthCareers.org initiative (www.explorehealth careers.org). In 2007, the organization announced a sizable grant awarded to the American Dental Education Association (ADEA) to administer and expand a free interactive health career website explaining dental careers and providing easy access for potential students seeking information.

\section{The Educational Pipeline}

Efforts to enhance awareness about a genetic counseling career among underrepresented minorities should start not only in high school, but earlier in middle and even elementary school. The Bureau of Health professions, housed within the Health Resources and Service Administration (HRSA) developed a comprehensive site through the "Kids Into Health Careers" initiative (Gilchrist and Rector 2007). Realizing that career aspirations and one's career identity begins to develop as early as the second grade, the Kids Into health Careers initiative has in place engaging curricula for educators, students and their parents in English, Spanish and other languages.

Parent involvement in students' education has been highly predictive of enrollment in higher education (Gilchrist and Rector 2007). In lower socioeconomic groups, parents may be unable to serve as "pathfinders" for their children, who in turn need to rely heavily on school counselors and teachers for career guidance. Career counselors may not be well informed about health careers options beyond the most visible careers in nursing and medicine. To that end, genetic counselors can also make themselves available to give career day presentations at various schools in their areas, with an emphasis on those with a diverse student body.

\section{Post-Secondary Recruitment Strategies}

Responses related to recruitment by Oh and Lewis' (2005) sample, and data from the diversity survey suggest that recruitment strategies in college may be quite successful in attracting people into the genetic counseling profession. The profession should continue to devote efforts to recruit college students to the genetic counseling profession, and they will do well to target colleges with high minority enrollment as well as community colleges. The AAMC's data showing an increase in minority students choosing biology and science majors are encouraging and should be capitalized; specifically, freshman and sophomore biology and psychology major students should be targeted and mentored to apply for genetic counseling programs.

Importantly, recruitment should expand to students with non-traditional career paths, such as those who are enrolled in programs that combine the 2 and 4 year college experience and health professionals seeking a career change. Another untapped resource is foreign-trained health professionals who may not be able to practice in their original vocations because of accreditation issues, and who are considering career changes. These individuals are by-or multi-lingual and their multicultural skills could prove to be a great asset to the profession as well as identify a new purpose for themselves.

\section{Mentoring}

Faculty and peer mentoring is key to assisting students to thrive in an academic climate in which they are underrepresented. Importantly, the fact that the NSGC has few African-American and Hispanic members makes for a professional climate that likely is challenging to members from these backgrounds. Minority students could be paired with diverse faculty and those who share their interests from related fields in their institution or with genetic faculty from other institutions in the event that such mentors are in short supply in their own institutions. Lastly, students can be encouraged to join diverse student groups in their institutions for peer support.

\section{Efforts by Program Directors}

It is important that program directors remain current regarding minority recruitment literature, best practices and national standards. They should continually explore 
resources in their own institutions, partner with diversity recruiters, and participate in institutional marketing efforts to groups that are under-represented in higher education. Program directors should also identify students who for whatever reason may experience cultural isolation or disadvantage and provide them with support and mentoring to maximize their training experience.

As educators, program directors have the obligation not only to promote disadvantaged students but also to assure an equitable and supportive learning environment. Some students may not have the same opportunities that other students have and their learning styles, expression choices and classroom needs may be different (Gilchrist and Rector 2007). Disadvantaged students may feel vulnerable, and fear discrimination, and they may struggle with trying to "fit in" with others, leading to unease and anxiety. Moreover, foreign-born students may experience communication barriers in a field heavily reliant on communication skills. These students may have difficulty in writing and verbal communications and struggle to remain afloat. Program directors must be open to exploring the cultural responsiveness and adequacy in the class room and clinical settings and be amenable to interventions such as cultural competency education for themselves, their program faculty and supervisors, and their students.

\section{Conclusions}

In order to best meet the needs of the entire American public the genetic counseling profession must move towards diversification and inclusion as a top priority. To meet this goal we must be willing to challenge our current practices and be ready for a sweeping institutional and professional "cultural change." The rewards of such a move are enormous and involve all of us in every aspect of our professional existence. In order to achieve this goal we need to employ bold and courageous tactics which will make us stronger as a profession and greatly enhance our ability to serve the public.

\section{References}

Agrawal, J. R., Vlaicu, S., \& Carrasquillo, O. (2005). Progress and pittfalls in underrepresented minority recruitment: Perspectives from the medical schools. Journal of the National Medical Association, 97(9), 1226-1231.

All Nursing Schools. (2007). Nursing Programs for Minorities. Retrieved 6/27/07, from http://www.allnursingschools.com/faqs/ diversityfaq.php.

Association of American Medical Colleges. (2006a). Diversity in the physician workforce: facts and figures. Washington, DC.

Association of American Medical Colleges. (2006b). New analysis reveals growing gap between undergrduates and medical school applicants. Press Release Retrieved 12/25/06, from http://www. aamc.org/newsroom/pressrel/2006/061116.htm.
Barbee, E. L., \& Gibson, S. E. (2001). Our dismal progress: The recruitment of non-whites into nursing. Journal of Nursing Education, 40(6), 243-244.

Barnes, R. (2007, 6/29/07). Divided court limits use of race by school districts. The Washington Post. Retrieved 7/1/07, from http:// www.washingtonpost.com/wp-dyn/content/article/2007/06/28/ AR2007062800896 pf.html.

Bell, J. (1998). The new genetics in clinical practice. British Medical Journal, 316, 618-620.

Betancourt, J. R., Green, A. R., Carrillo, J. E., \& Ananeh-Firempong, O., II (2003). Defining cultural competence: A practical framework for addressing racial/ethnic disparities in health and health care. Public Health Reports, 118(4), 293-302.

Boldt, A. (1994). Professional Status Survey. Perspectives in Genetic Counseling.

Brady, P. (2004). Med schools' minority enrollment stays low. The Yale Daily News.

Bumgarner, S. D., Means, B. H., \& Ford, M. J. (2003). Building bridges: from high school to healthcare professional. Journal for Nurses in Staff Development, 19(1), 18-22, quiz 23-14.

Bureau of Labor Force Statistics. (2006). Employed and experienced unemployed persons by detailed occupation, sex, race, and Hispanic or Latino ethnicity, national average 2005. Retrieved 6/27/07, from http://www.bls.gov/cps/\#overview.

Cohen, J. (2005). Increasing diversity in the workforce is one solid way to Prevent Disparities in Healthcare. Retrieved 4/21/06, from http://www.medscape.com/viewarticle/514893.

Cohen, J. J., Gabriel, B. A., \& Terrell, C. (2002). The case for diversity in the health care workforce. Health Affairs (Millwood), 21(5), 90-102.

Cohen, J., \& Steinecke, A. (2006). Building a diverse physician workforce. Journal of the American Medical Association, 296(9), $1135-1137$.

Cooksey, J. A., Forte, G., Benkendorf, J., \& Blitzer, M. G. (2005). The state of the medical geneticist workforce: findings of the 2003 survey of American Board of Medical Genetics certified geneticists. Genetics in Medicine, 7(6), 439-443.

Cooksey, J. A., Forte, G., Flanagan, P. A., Benkendorf, J., \& Blitzer, M. G. (2006). The medical genetics workforce: an analysis of clinical geneticist subgroups. Genetics in Medicine, 8(10), 603614.

Cordes, B., \& Miller, G. (2005). Inequality of education in the United States. Retrieved 6/29/07, from http://cte.rockhurst.edu/FileUp loads/Cordes.pdf.

Dennery, P. A. (2006, Jul). Training and retaining of underrepresented minority physician scientists - an African-American perspective: NICHD AAP workshop on research in neonatal and perinatal medicine. Journal of Perinatology, 26(Suppl 2), from http:// www.ncbi.nlm.nih.gov/entrez/query.fcgi?cmd=Retrieve $\& \mathrm{db}=$ PubMed\&dopt $=$ Citation\&list uids $=16801969$.

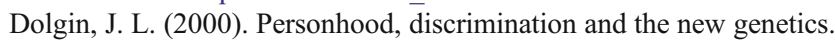
Brooklyn Law Review, 66, 755-822.

Doyle, D. L. (1996). Professional Status Survey results. Perspectives in Genetic Counseling, 18, 1-8.

Duffy, F., West, J., Wilk, J., Narrow, W., Hales, D., \& Thompson, J. (2004). Mental health practitioners and trainees. Rockville, MD: US Department of Health and Human Services.

Educational Broadcasting Corporation. (2004). Slavery and the making of America: The slave experience: Education, arts and culture. Retrieved 6/29/07, from http://www.pbs.org/wnet/slav ery/experience/education/history2.html.

Farmer, J. (2000). Professional Status Survey. Perspectives in Genetic Counseling, 22(4), S1-S12.

Fine, B., Baker, D., \& Fiddler, M. (1996). ABGC Consensus Development Consortium. Journal of Genetic Counseling, 5(3), 113-121. 
Fletcher, A., Williams, P. R., Beacham, T., Elliott, R. W., Northington, L., Calvin, R., et al. (2003). Recruitment, retention and matriculation of ethnic minority nursing students: a University of Mississippi School of Nursing approach. Journal of Cultural Diversity, 10(4), 128-133.

Friedman, A. L. (2007). Enhancing the diversity of the pediatrician workforce. Pediatrics, 119(4), 833-837.

Gardner, J. (2005a). A successful minority retention Project. Journal of Nursing Education, 44(12), 566-568.

Gardner, J. (2005b). Barriers influencing the success of racial and ethnic minority students in nursing programs. Journal of Transcultural Nursing, 16(2), 155-162.

Gilchrist, K. L., \& Rector, C. (2007). Can you keep them? Strategies to attract and retain nursing students from diverse populations: best practices in nursing education. Journal of Transcultural Nursing, 18(3), 277-285.

Gonzalez, L. S., Kearns, E. H., Lafferty, S., Lampignano, J., \& Pappas, V. M. (2000). The middle school mentoring program in allied health: a proposed model. Journal of Allied Health, 29(2), 114-119.

Grumbach, K., \& Chen, E. (2006). Effectiveness of University of California postbaccalaureate premedical programs in increasing medical school matriculation for minority and disadvantaged students. Journal of the American Medical Association, 296(9), 1079-1085.

Grumbach, K., Coffman, J., Granada, P., Munoz, C., \& Rosenoff, E. (2003). Strategies for improving the diversity of the health professions. San Francisco, CA, USA: The California Endowment.

Institute of Medicine (2001). The right thing to do the smart thing to do. Washington, DC.

IOM (2002). Unequal treatment: Confronting ethnic and racial disparities in health care. Washington, DC, USA: The National Academic Press.

IOM (2004). In the nation's compelling interest: Ensuring diversity in the health-care workforce. Washington, DC, USA: Institute of Medicine.

Komaromy, M., Grumbach, K., Drake, M., Vranizan, K., Lurie, N., Keane, D., et al. (1996). The role of black and Hispanic physicians in providing health care for underserved populations. New England Journal of Medicine, 334(20), 1305-1310.

Kosanovich, K. (2006). Employed and experienced unemployed persons by detailed occupations, sex, race, and Hispanic or Latino ethnicity, annual average 2005 (Source: Current Population Survey). In I. Mittman (Ed.), Bureau of Labor Force Statistics (BLFS).

Lea, D. H., Williams, J. K., Cooksey, J. A., Flanagan, P. A., Forte, G., \& Blitzer, M. G. (2006). U.S. genetics nurses in advanced practice. Journal of Nursing Scholarship, 38(3), 213-218.

Lee, M., \& Coulehan, J. L. (2006). Medical students' perceptions of racial diversity and gender equality. Medical Education, 40(7), 691-696.

Lega, M., McCarthy Veach, P., Ward, E. \& Leroy, B. (2005). Who are the next generation of genetic counselors? A survey of students. Journal of Genetic Counseling, 14(5), 395-407.

Lin-Fu, J., Lloyed-Puryear, M., Khoury, M., Burke, M., \& Thomson, E. (2000). Access to genetic services in the United States: A challenge to genetics in public health. In Genetics and Public Health in the 21st Century, (pp. 273-289). New York: Oxford University Press.

Marcelin, G. E., Goldman, L., Spivey, W. L., Eichel, J. D., Kaufman, F., \& Fleischman, A. R. (2004). The Junior Fellows Program: motivating urban youth toward careers in health, science, and medicine. Journal of Urban Health, 81(3), 516-523.

Maton, K. I., \& Hrabowski, F. A., III (2004). Increasing the number of African American PhDs in the sciences and engineering: a strengths-based approach. American Psychologist, 59(6), 547556.

Matsui, J., Liu, R., \& Kane, C. M. (2003). Evaluating a science diversity program at UC Berkeley: more questions than answers. Cell Biology Education 2(2), 117-121.

McNeal, G. J., \& Walker, D. (2006). Enhancing Success in Advanced Practice Nursing: a grant-funded project. Journal of Cultural Diversity, 13(1), 10-19.

Mittman, I. (1997). Building bridges: Counselors promoting diversity. Perspectives in Genetic Counseling, 19(1), 6.

Moreno, J., Smith, D. G., Clayton-Pedersen, A. R., Parker, S., \& Teraguchi, D. H. (2006). The revolving door for underrepersented minority faculty in higher education.

Moy, E., \& Bartman, B. A. (1995). Physician race and care of minority and medically indigent patients. Jama, 273(19), 1515-1520.

NSGC (1991). NSGC position statement on access to care. Retrieved 8/31/07, from http://www.nsgc.org/about/position.cfm\#Access.

NSGC (1992). Genetic counselors and their clients. Retrieved 8/31/07, from http://www.nsgc.org/about/codeEthics.cfm\#sec_2.

NSGC (2003). NSGC Strategic Plan 2004-2006. Retrieved 2/17/07, from http://www.nsgc.org/about/strategicPlan.cfm.

Oh, T., \& Lewis, L. J. (2005). Consideration of genetic counseling as a career: Implications for diversifying the genetic counseling field. Journal of Genetic Counseling, 14(1), 71-81.

Parrott, S., \& Del Vecchio, M. (2007). Professional Status Survey 2006: National Society of Genetic Counselors, Inc.

Parrot, S., \& Manely, S. (2004). National Society of Genetic Counselors, Inc. Professional Status Survey 2004: NSGC.

Price, E. G., Gozu, A., Kern, D. E., Powe, N. R., Wand, G. S., Golden, S., et al. (2005). The role of cultural diversity climate in recruitment, promotion, and retention of faculty in academic medicine. Journal of General Internal Medicine, 20(7), 565571.

Raymond, W. E., \& Lue, R. A. (2006). Shared challenges: Shared solutions. TheScientist: Magazineof the Life Sciences Retrieved 11/30/2006, from http://www.the-scientist,com/2006/11/01/s38/1.

Saha, S., Taggart, S. H., Komaromy, M., \& Bindman, A. B. (2000). Do patients choose physicians of their own race? Health Affairs (Millwood), 19(4), 76-83.

Schnieder, H. (1998). Professional Status Survey. Perspectives in Genetic Counseling, 20(3), S1-S8.

Schoonveld, K. C., Veach, P. M., \& Leroy, B. S. (2007). What is it like to be in the minority? ethnic and gender diversity in the genetic counseling profession. Journal of Genetic Counseling, 16(1), 5369.

Smith, S. C., Warren, N. S., \& Misra, L. (1993). Minority recruitment into the genetic counseling profession. Journal of Genetic Counseling, 2(3), 171-181.

Stewart, S. R., Pool, J. B., \& Winn, J. (2002). Factors in recruitment and employment of allied health students: preliminary findings. Journal of Allied Health, 31(2), 111-116.

Sullivan, L. W. (2004). Missing persons: Minorities in the health professions. Retrieved 3/11/08, from http://www.aacn.nche.edu/ Media/pdf/SullivanReport.pdf.

Terrel, C., \& Beaudreau, B. (2003). 3000 by 2000 and beyond: Next steps for promoting diversity in the health professions. Journal of Dental Education, 67(9), 1048-1052.

Thomson, W. A., Miller, L. M., Shargey, B. O., Smith, Q. W., \& Denk, J. P. (1991). A follow-up study of allied health educational and career interests of graduates of a high school for health professions. Journal of Allied Health, 20(4), 233-244.

Uhlmann, W. (1992). Professional Status Survey. Perspectives in Genetic Counseling, 14(2), 7-10.

Uhlmann, W. (2000). Task force appointed. Perspectives in Genetic Counseling, 22(1), 2. 